\title{
Cuando se encuentran cultura fan y podcasting: las nuevas relaciones con la audiencia en 0 Caso Evandro
}

\author{
Debora Cristina Lopez \\ Universidade Federal de Ouro Preto / Universidade \\ Federal do Paraná, Brasil \\ deboralopezfreire@gmail.com \\ https://orcid.org/0000-0002-1030-1996
}

\author{
Aline Monteiro Homssi \\ Universidade Federal de Minas Gerais, Brasil \\ alinemonteiro@gmail.com \\ https://orcid.org/0000-0001-5430-5983
}

\section{When fan culture and podcasting meet: New relationships with the audience in 0 Caso Evandro}

\begin{abstract}
RESUMEN ABSTRACT
En este artículo analizamos, desde la perspectiva teórica de los estudios de fans, dos de los grupos creados, en redes sociales online, para la discusión de $O$ Caso Evandro, cuarta temporada del podcast Projeto Humanos. 0 Caso Evandro discute las complejidades, contradicciones e implicaciones de un crimen ocurrido en Brasil en 1992, con muchos elementos e implicaciones hasta la fecha. El niño Evandro Ramos Caetano fue brutalmente asesinado y siete personas fueron acusadas. Analizamos los grupos de discusión creados en las plataformas de Facebook y Reddit por los oyentes del podcast, con el propósito de discutir en exclusiva la cuarta

temporada del podcast. Nuestra muestra corresponde a publicaciones realizadas de enero a abril de 2021, correspondientes a 120 días. Nuestra hipótesis es que esta temporada del programa potencia el papel de la audiencia característica de la radio al migrar a las plataformas digitales y a la dinámica de consumo del podcasting, explorando características de la llamada cultura del fan. Adoptamos una metodología de estudio descriptiva, construida a partir de la basis teórica adoptada. Como resultado, tenemos seis ejes que indican nuevas relaciones de audiencia con el podcast y que pueden indicar formas de involucrar a la audiencia en nuevas pro-

In this article, we analyze, from the theoretical perspective of fan studies, two of the groups created, in online social networks, for the discussion of 0 Caso Evandro (The Evandro (ase), fourth season of the Projeto Humanos podcast. 0 Caso Evandro discusses the intricacies, contradictions and implications of a crime that took place in Brazil in 1992, in the State of Paraná, with many elements and implications to date. The boy Evandro Ramos Caetano was brutally killed and seven people were accused. We analyze discussion groups created on Facebook and Reddit platforms by podcast listeners, with the purpose of discussing the fourth season of the podcast. Our sample corresponds to publications carried out from January to April 2021, corresponding to 120 days. Our hypothesis is that this season of the program enhances the role of audience - as in radio productions - by migrating to digital platforms and to the fruition dynamics of podcasting, exploring characteristics of the so-called fan culture. We adopted a descriptive study methodology, built from the theoretical scope adopted. As a result, we have six axes that indicate new audience relationships with the podcast and that can indicate ways to engage the audience in new productions.
\end{abstract}

ducciones.

\section{PALABRAS CLAVE KEYWORDS}

Podcasting; Radio expandida; Cultura fan; Estudios de fan; 0 Caso Evandro.

Podcasting; Expanded radio; Fan culture; Fan studies; o Caso Evandro. 


\section{Introducción}

La radio es tradicionalmente un espacio para "contar historias". Los sujetos, los personajes, la proximidad narrativa siempre han sido protagonistas en el medio, incluso antes de su inserción en plataformas digitales. En la época dorada de la radio, eran frecuentes los programas de humor relacionados con las costumbres; programas de asesoramiento sentimental, que exponen la vida cotidiana de la audiencia; producciones que comentaban el día a día de los artistas acercándolos a la realidad de los oyentes; el deporte, que, además de resultados y agenda, presentó historias de superación de dificultades; documentales, reportajes y especiales que tenían a los personajes como conductor.

Históricamente, la radio ha superado desafíos, ha cambiado su programación, se ha adaptado a las variaciones tecnológicas y las nuevas prácticas comunicacionales. La permanencia en medio de estos cambios es la relación con los sujetos, ya sean parte de la audiencia o protagonistas de los hechos. Con la inserción en la nueva ecología de los medios y la remisión a una radio multiplataforma y multimedia, la historia de vida aparece como una continuidad, quizás incluso como una potencialización (Palacios, 2003) debido a la intensificación de las prácticas de intercambio y exposición diaria que caracterizan la red. "El renovado interés por las historias radiales coincide con la obsesión moderna por las historias personales. Hay más formas que nunca de compartir cada detalle de nuestras vidas con el mundo a través de la plétora de plataformas digitales y redes sociales " (Lindgren, 2014, p. 64).

Estas historias personales, presentadas por la autora, no están relacionadas exclusivamente con el audio en plataformas digitales, sino que siempre han formado parte de la radio (Ferraretto, 2014). Sin embargo, al ocupar estos espacios, la radio adquirió una nueva relación con la audiencia (Lopez, 2016) y potenció la experimentación narrativa (Lopez, Viana y Avelar, 2018). La radio transmedia descubre así un espacio de diálogo con las audiencias, de intercambio, y se encuentra tensada por nuevas dinámicas de producción y relaciones propias de la cultura de la conexión (Jenkins, Green y Ford, 2014).

Entre los retos de esta nueva relación construida con la audiencia se encuentra la llamada cultura fan (Jenkins, 2006, 2015; Shirky, 2011, 2012), que revela un consumidor activo, conectado, que produce, comenta y está directamente vinculado a una producción y a sus personajes. Este vínculo, muchas veces denominado patológico' (Jenson, 1992), eleva a los sujetos que componen la historia -personajes, actores, autores- a la condición de celebridad que es, a la vez, amiga, cercana y, por tanto, debe ser defendida e idolatrada. Observamos cada vez más movimientos para acercar este perfil de la relación entre audiencia y producto al periodismo, en paralelo con el crecimiento de la exploración de narrativas complejas, transmedia y el desarrollo de universos narrativos que involucran al oyente (Lopez, Viana y Avelar, 2018).

En este artículo analizamos el fenómeno de la radio transmedia en un podcast. Analizamos las manifestaciones de los fanáticos y de la llamada cultura fan en los grupos que discuten 0 Caso Evandro, cuarta temporada del podcast Projeto Humanos en Reddit y Facebook. Estos espacios fueron seleccionados por tener una participación constante de los fans, incluso en los descansos entre micro temporadas de podcasts, y por tener entre los sujetos que se manifiestan una de las protagonistas de la historia, Beatriz Abagge. A través de una investigación descriptiva, construida a partir de las características de la cultura fan, el fenómeno del podcasting y la radio transmedia, buscamos comprender el papel de este fan en el dibujo de la relación con el objeto de devoción y el desarrollo de la narrativa.

La muestra analizada comprende las publicaciones realizadas en los dos grupos de discusión - Projeto Humanos - Histórias reais sobre pessoas reais, en Reddit; Discutindo o Caso Evandro - Projeto Humanos, en Facebook - del 1 de enero al 30 de abril de 2021, totalizando 120 días de actividades. Todas las publicaciones del período fueron impresas y analizadas bajo siete ejes de análisis: 1) marcas de producción colaborativa; 2) teorías de la conspiración; 3) actualizaciones; 4) dudas; 5) expansión del universo; 6) análisis de sonido por fans; y 7) consumo compartido de episodios.

\section{Podcasting cómo objeto de estudios}

La conceptualización del podcasting sigue siendo un desafío en la academia. Debido a su vínculo directo con las tecnologías de distribución y circulación, el concepto a menudo se reduce a una perspectiva técnica, sin tener en cuenta cuestiones como las prácticas sociales en las plataformas digitales. En este artículo, consideramos el podcasting como un movimiento que integra la nueva ecología de los medios (Scolari, 2013), específicamente en la dinámica de la radio expandida (Kischinhevsky, 2016) o hipermedia (Lopez, 2017), que se desarrolla en un contexto de innovación narrativa y tecnológica.

Como nos recuerdan Lopez (2017) y Kischinhevsky (2016), la radio en plataformas digitales tiene una nueva configuración, que además de explorar el lenguaje parasonoro² ${ }^{2}$ también se expande a múltiples plataformas. De esta forma, es posible pensar en dinámicas de consumo alteradas, que se mueven entre espacios y prácticas de comunicación. En este contexto, las redes sociales son espacios de circulación y producción de contenidos para podcasting, ya sean de productores o de audiencias activas (Masip, 2014). Estas audiencias y dos nuevas configuraciones, recuerda el autor (2014; 2015), tienen múltiples funciones que generan desafíos a las prácticas periodísticas (procedimentales y éticas) y, al mismo tiempo, 
permiten una comprensión amplia de la audiencia, en una perspectiva colectiva, de compartir y formar comunidad.

En el podcasting es posible, como recuerdan Martínez-Costa, Müller y Villar (2019), explotar características que benefician al oyente, garantizando relaciones más cercanas y caso individualizadas de consumo del contenido sonoro. "El podcast permite empaquetar de modo

asincrónico sus contenidos y ofrecerlos a demanda a un usuario selectivo y orientado a consumir lo que es verdaderamente de su interés" (Martínez-Costa, Müller y Villar, 2019, p. 59).

Esta complejidad del objeto sonoro explicado en el podcasting se manifiesta tanto en la relación con la audiencia y en la diversidad de géneros y formatos de producción como en la expansión de las modalidades narrativas activadas en la podósfera. Como nos recuerda Bonini (2015), vivimos en la segunda era del podcasting, que incluye una mayor difusión de contenidos, formación de nuevos productores y expansión del reportaje humanizado. Esta posibilidad de renovación radiofónica basada en el podcasting y la humanización potenciada por la perspectiva personal inspirada en la estructura narrativa del nuevo periodismo (Lindgren, 2016) lleva las historias de vida al centro del escenario.

Las múltiples dinámicas de escuchar podcasts también dialogan con el contenido presentado. Los podcasts informativos y de actualidad se apropian de las habilidades auditivas compartidas con otras actividades, acompañando a los oyentes en actividades domésticas o cuando están en movimiento. Los podcasts narrativos, más personales e inmersivos, representan uno de los aspectos más destacados de la hiperespecialización que caracteriza esta segunda era del podcasting, especialmente en relación con las historias de no ficción (McHugh, 2016). Estas producciones conducen a un refuerzo de la experiencia auditiva individual que simula el diálogo con un amigo cuando se escucha a través de auriculares (Lindgren, 2016). La inmersión narrativa (Domínguez-Martín, 2015) considera las posibilidades interactivas, las experiencias sensoriales y la promoción del carácter activo del usuario en la historia. De esta forma, como plantean Cordeiro y Costa (2016), se podría explorar el potencial para modificar la experiencia auditiva y las sensaciones de la audiencia a partir de nuevos formatos derivados del desarrollo técnico y tecnológico.

Este potencial innovador es también un escenario para el desarrollo de narrativas innovadoras y para explorar el potencial de las plataformas a través de narrativas transmedia. Lopez, Viana y Avelar (2018) destacan el potencial de los podcasts narrativos para dialogar con contenido atemporal, profundo, más cercano a la audiencia y más interactivo. Para las autoras, la aproximación y la interacción ocupan un espacio estratégico en lo que se puede llamar radio transmedia, considerando el podcasting como parte del contexto productivo de la radio en plataformas digitales. "La perspectiva de la participación activa del usuario en la construcción de la narrativa y la posibilidad de compartirla en las redes sociales son, en este caso, aspectos relevantes en su caracterización como un experimento transmedia". (Alzamora y Tárcia, 2012, p. 31).

Como dijimos, entendemos el podcasting como parte de la radio en plataformas digitales. Esto nos lleva a una observación multidimensional de los movimientos de delimitación y especificación del objeto. Si bien definimos el audio como punto de partida y como eje para la comprensión del fenómeno, asumimos la existencia del papel de la narrativa parasonora y la dinámica interactiva no sonora y el desencadenamiento emocional para dar respuesta a las preguntas de este estudio. De esta manera, los conceptos de cultura de fans, podcasting y producción de sonido transmedia asumen pesos similares en el enfoque construido. Nos damos cuenta de que las variaciones en el perfil de las audiencias, aunque no ignoran la trayectoria de los radioescuchas y sus dinámicas interactivas en el tiempo (Lopez, 2016), se ven directamente afectadas por las nuevas prácticas de comunicación, el consumo compartido y el potencial de creación de comunidades - característico de la Cultura Fan.

El fenómeno en el fan que expande su contenido compartido desde círculos de conversación cara a cara a redes sociales y plataformas digitales también afecta la radio (y el podcasting), impactando la circulación no solo desde las recomendaciones algorítmicas, sino también desde las recomendaciones personales y el propio acto de compartir, comentar o criticar la escucha realizada. Es tanto la búsqueda de iguales, el compartir intereses y la aceptación, como el posicionamiento crítico, el ridículo, la negación de los contenidos consumidos. Ambas acciones, enfatizamos, están asociadas a la búsqueda de la integración en un grupo, la formación de comunidades de interés y la construcción de teorías o argumentos colectivos. La multidimensionalidad del objeto, entonces, dialoga con áreas de interfaz y nos lleva a construir nuevas preguntas sobre radio y podcasting para que podamos entender las relaciones con la audiencia y con las formas de contar historias en sonido.

\section{La cultura fan}

En la llamada Cultura de Conexión, Jenkins, Green y Ford (2014) afirman que lo que importa es el público comprometido. Los autores creen que la actuación de esta audiencia es lo que determina el éxito o el fracaso de una producción mediática. Según ellos, antes de la digitalización de los medios, el desempeño de los fanáticos se medía por cifras de audiencia masivas. En la cultura de la conexión, estos datos son parte de una medición más amplia. La conexión del público con el objeto mediático ya no es vista solo por la audiencia masiva, sino por varios otros factores, que involucran las redes sociales online, la compra de productos licenciados, el acceso a extensiones narrativas transmedia y la conversación online y offline, a través de canales oficiales de los productores oa través de otros 
canales, como grupos de discusión en plataformas propietarias. Así, la Cultura de Conexión trajo un gran aprecio de parte del público que antes se veía con atrincheramiento: la afición. Así, de la audiencia masiva, se destaca el público comprometido; de esto, los fanáticos se destacan.

Los fanáticos de los productos mediáticos fueron, durante un largo período, evaluados como locos, lunáticos y exagerados, como señalan Adorno y Horkheimer (1985). En el texto de los pensadores alemanes, el cine y la radio son los encargados de crear una masa de público que, sin pensar críticamente, repita comportamientos y acciones de sus objetos de culto. Desde que Jenkins (2015) eliminó a los fanáticos de los productos de los medios de la condición de subcultura, y con la mayor visibilidad de los grupos de fanáticos a través de la convergencia de los medios, las actividades públicas han sido observadas más de cerca, tanto por los investigadores como por los productores de los medios. La visión negativa de los fans, como la de Adorno y Horkheimer (1985), ya no es dominante, como muestran los estudios de Jenkins, Green y Ford (2014).

Con la cultura de la convergencia, la conversación sobre productos mediáticos por parte del público ganó un lugar en los propios medios, expandiendo las interacciones cara a cara, mediadas o cuasi-mediadas (Thompson, 1998) y posibilitando encuentros con el público. Los sitios, blogs, foros y, más recientemente, los sitios de redes sociales se han convertido en espacios donde los fanáticos producen textos, ficciones, artes, imágenes y que también forman comunidades para discusiones, evaluaciones, intercambio de materiales y producción colectiva de conocimiento sobre el objeto de devoción. Como señala Shirky (2011), Internet ha permitido al público consumir medios no pasivos. Según él (2011), quienes participan actúan como si su opinión, acción o respuesta importara en el proceso comunicativo, y el grado de participación pública con productos mediáticos se amplió con el surgimiento del teléfono y, más recientemente, de internet. Por lo tanto, aunque la participación de la audiencia no fue creada por Internet, ciertamente fue mejorada por ella.

Ya sea dentro o fuera de Internet, los fanáticos se encuentran y se unen porque comparten el gusto por un objeto mediatico. Los grupos pueden fortalecerse con el amor y también con el odio hacia este objeto. Según Jenkins (2015), los grupos de fans se denominan fandons, un nombre que deriva de fan y kingdom. El fandom es, entonces, el "reino de los fans". La adherencia a los fandones suele ser gratuita. En los casos observados para esta investigación, los grupos que discuten 0 Caso Evandro en Facebook y Reddit, el ingreso de nuevos participantes en los grupos ocurre de acuerdo a las reglas de cada plataforma.

Facebook permite que sus grupos de discusión sean públicos, privados o secretos. Cualquier persona que tenga un perfil en esta plataforma puede acceder a los grupos públicos, y cualquiera puede ver la discusión. Sin embargo, solo las personas que forman parte del grupo participan en la discusión. Cualquier persona que tenga un perfil en esta plataforma puede acceder a los grupos privados, pero la discusión no se muestra a las personas que no forman parte del grupo. Para unirse al grupo y acceder a la discusión, el candidato debe ser aprobado por los administradores del grupo. Finalmente, los grupos secretos no aparecen en la búsqueda, volviéndose invisibles para quienes no forman parte de ella. La participación es posible con previa invitación de los administradores. El grupo Discutindo o Caso Evandro - Projeto Humanos, en Facebook, es privado: puede ser visto por cualquier persona con un perfil en la plataforma, pero las discusiones solo pueden ser accedidas por aquellos que son miembros del grupo.

Reddit es un sitio de foro de discusión abierto. Cualquiera puede acceder a subReddits, grupos formados en torno a un tema. Sin embargo, para publicar, comentar y votar sobre el contenido, debe tener un perfil en la plataforma y unirse a la página del grupo. El subReddit Projeto Humanos: histórias reais sobre pessoas reais, por lo tanto, puede ser visto por cualquier persona con acceso a Internet, pero las discusiones (publicaciones, comentarios y votos) solo las realizan personas con un perfil en la plataforma y que son miembros del subReddit.

Según Shirky (2011), el intercambio de información tiene lugar en cuatro niveles: personal, común, público y cívico. El nivel personal es individual y va de un extremo a otro. El intercambio común es entre personas que comparten los mismos intereses. Este tipo de intercambio es común en los grupos de fans, que brindan información y contenido diverso a sus compañeros. El intercambio público, según Shirky (2011), amplía el acceso del contenido a otras personas, fuera de las agrupaciones. Los grupos de fans también practican este tipo de intercambio de contenido. Finalmente, Shirky (2011) aporta el compartir cívico, que se interesa por las transformaciones sociales para la sociedad en su conjunto. Más recientemente, los grupos de fans se han involucrado en el activismo digital, practicando el intercambio cívico. Los grupos analizados en esta investigación practican dos tipos de compartir, según el autor: común y público. Destacamos que, al ser un grupo privado, el grupo de Facebook comparte contenidos en común y en restricto, mientras que el subReddit, por las características de la plataforma, trabaja con contenidos públicos.

Para fomentar la conversación entre fans, ya sea en las redes sociales online o fuera de ellas, los productores de medios utilizan algunas estrategias. Uno de ellos, presente en el podcast Projeto Humanos, es la serialidad. Según Teixeira (2020), la característica que hace que algo sea reconocido como serie es la serialidad. El autor llama la atención sobre las diferencias entre los objetos agrupados bajo la serie de adjetivos: permiten el reconocimiento del conjunto. Así, la cuarta temporada del podcast 0 Caso Evandro presenta 36 capítulos de una misma historia. Son las diferencias que existen en cada 
capítulo, y no sus similitudes (por ejemplo, las viñetas de apertura y cierre o la presencia del mismo narrador), las que caracterizan al set como una temporada y, más precisamente, como una historia única serializada. En la Cultura de Convergencia (Jenkins, 2009) y la Cultura de Conexión (Jenkins, Green y Ford, 2014), la serialidad se presenta como una característica importante para la participación de la audiencia. Como también señala Teixeira (2020), la serialidad permite que las narrativas se presenten de tal manera que la audiencia necesite seguir los capítulos en secuencia para tener conocimiento del conjunto.

La serialidad es también un elemento importante, según Jenkins (2009), para que una narrativa se desarrolle de forma transmedia. Así, de un mismo universo narrativo se pueden extraer diferentes productos que amplían la narrativa y muestran al público diferentes formas de acceder a ella. Lessa (2020) denomina a los productos que parten de una narrativa madre "extensiones transmedia". En el caso de la cuarta temporada de Projeto Humanos, 0 Caso Evandro tiene três principales extensiones transmedia: la serie documental televisiva, producida por Glaz y emitida por el servicio de streaming Globo Play en 2021, y el libro 0 Caso Evandro: Sete acusados, dos policías, el cuerpo y una trama diabólica, escrito por el presentador de podcast Ivan Mizanzuk y publicado por Harper Collins Brasil (2021). También es importante registrar el contenido multimedia disponible en la "Enciclopedia do Caso Evandro", un sitio con documentos y ampliaciones producidos por el propio Mizanzuk y publicados junto con los episodios del podcast. Con extensiones transmedia, las audiencias comprometidas, y especialmente los fanáticos de la narrativa, pueden acceder a nuevas formas narrativas para una misma historia, con características de los medios en los que se están contando. Por otro lado, también se puede acercar una nueva audiencia, que puede acceder a la historia principalmente a través de medios distintos al podcast, ampliando su campo de acción.

Es importante enfatizar que las características narrativas del podcast también permiten que la audiencia sea capturada por la trama. Teixeira (2020) denomina "ganchos" a los elementos narrativos que apuntan y prometen la continuidad de la historia en otro capítulo de la misma serie. El autor lo llama "recuperación" cuando se retoma el gancho sobrante del episodio anterior, continuando la narrativa. Además, llama "saga" al tipo de narrativa que entrelaza varias historias, contándolas en arcos narrativos, esparcidos a lo largo de los episodios. De esta forma, la audiencia sigue el producto siguiendo los episodios serializados y, a través de ellos, puede convertirse en una audiencia comprometida y, más tarde, en un fan.

\section{0 Caso Evandro y los fans en Reddit y Facebook}

O Caso Evandro, que analizamos en esta investigación, es la cuarta temporada del podcast narrativo serializado Projeto
Humanos, liderado por el diseñador y profesor Ivan Mizanzuk. Cada temporada del Projeto Humanos se centra en un tema específico, teniendo siempre como guía la historia real de los personajes y las técnicas de narración contemporáneas. Inspirado por el podcast estadounidense Serial, el presentador Ivan Mizanzuk decidió traer una verdadera historia policial brasileña, aún inconclusa, pero ya prescrita por el sistema judicial brasileño. La elección del Caso Evandro también tiene implicaciones personales, ya que el podcaster era un niño y vivía en el Estado de Paraná, en el momento en que ocurrieron los hechos.

En la ciudad costera de Guaratuba, en el interior de Paraná, el niño Evandro Ramos Caetano, de 6 años y 7 meses, desapareció en abril de 1992. La desaparición movilizó un grupo táctico de la policía civil del Estado, que comenzó a investigar. Cinco días después de la desaparición, se encuentra el cuerpo de Evandro con graves mutilaciones. La investigación se prolonga durante tres meses, sin conclusiones. En julio del mismo año, otro grupo, este de la Policía Militar de Paraná, sin tener contacto con la investigación en curso, presenta a siete personas como responsables del crimen y señala que formaban parte de una secta satánica, y que la muerte del niño Evandro se realizó en un ritual de magia negra.

Para narrar esta historia, la cuarta temporada de Projeto Humanos contó con 36 episodios, publicados del 30 de octubre de 2018 a noviembre de 2020, más dos episodios extras, publicados el 24 de junio de 2019 y el 8 de julio de 2021. Además, debido a la complejidad del caso y debido a la gran cantidad de personajes involucrados, se creó una enciclopedia en formato wiki, que trae materiales extra, como el mapa de la ciudad, la lista de personajes y sus implicaciones en el caso, documentos oficiales, otros audios, videos y resúmenes, a los que se puede acceder por episodio o por tema.

La historia narrada trae muchos elementos que desencadenan las emociones de los oyentes. El primero y más evidente es el asesinato de un niño de 6 años. Aún quedan implicaciones religiosas añadidas tras la detención de los siete acusados: parte de ellos participaba en religiones brasileñas de origen africano, que hasta el día de hoy sufren prejuicios en la sociedad. Las dos religiones, Umbanda y Candomblé, son diferentes en sus prácticas y principios, pero son tratadas como una sola durante las investigaciones. Se amplió la presencia del sacrificio de animales en algunas de sus prácticas, como si ambos permitieran el sacrificio humano, que no es el caso. Los motivos señalados por los acusadores para que los siete implicados sean considerados culpables permean el éxito económico y financiero de un emprendimiento y, también, la victoria en la política municipal. Tales viles motivos alentaron la furia del pueblo contra los imputados durante sus detenciones $\mathrm{y}$, posteriormente, en los juicios y sus consecuencias. Los siete imputados alegan que fueron torturados y obligados a confesar un delito que no cometieron. Los diversos desen- 
cadenantes emocionales causados tanto por la historia como por su narrativa impulsan a los oyentes a conectarse con la trama.

Aunque siete personas han sido acusadas del asesinato de Evandro, la narrativa en un podcast serial hizo que la audiencia discutiera la culpabilidad del acusado y otras implicaciones de la trama, haciendo que la narrativa fuera ficticia. El comportamiento del público, buscando en el podcast y también en las recopilaciones de noticias digitalizadas de la época, posibles pistas y desarrollos del caso, abrió espacio para amplios debates en las redes sociales online.

Dos de los grupos de discusión creados, el subReddit Proyecto Humano - Historias reales sobre personas reales y el grupo de Facebook Discusión del caso Evandro - Proyecto humano son objetos de observación continua. Al final del período de observación - 1 de enero al 30 de abril de 2021 - 10.242 personas estuvieron presentes en ambos grupos, discutiendo tanto el evento - el asesinato del niño Evandro y sus implicaciones - como el podcast - la cuarta temporada del podcast Human Project. Los dos espacios fueron creados por los oyentes, con el objetivo de ampliar el debate. Ambos brindan a la audiencia del podcast un espacio de mayor libertad de expresión y debate, con la mediación de los propietarios de las páginas y las reglas impuestas por ellos. Además, permiten la colaboración en la generación de contenidos sobre la narrativa, lo que Lévy (2003) denominó inteligencia colectiva. Los contenidos descubiertos se comparten en los grupos, actualizando a los participantes sobre nuevas formas de observar el mismo fenómeno.

Por las peculiaridades del caso, existe un movimiento, en los grupos analizados, de "elección", en el que los integrantes expresan preferencia por uno o más de los personajes de la trama. La primera toma de posición de los participantes del grupo proviene de la pregunta "¿culpable o no culpable?", Aplicada a cada uno de los siete acusados. Hay otras preguntas, como "¿hubo o no tortura?", "Si los siete imputados no son culpables, ¿quién mató a Evandro?". También hay una pregunta que no parece legítima, pero que se repite en los grupos: "aunque hubo tortura, ¿son culpables los siete imputados?". Las preguntas planteadas están asociadas, en cierta medida, con las relacionadas con historias de ficción de crimen y misterio: "¿quién mató?", "¿Quién se benefició de alguna manera del crimen?", "¿Dónde estaba este personaje en el momento del crimen?"," ¿Cuáles son los impactos de las acciones de dicho personaje en la trama? ".

Ambos espacios, al mantener una intensa discusión sobre el caso, llamaron la atención de los involucrados en el caso. Una de las acusadas del asesinato de Evandro, Beatriz Abagge, fue la primera en estar presente en los grupos. Activa en los debates, mantiene una posición firme al defender la inocencia de los imputados y al afirmar que todos fueron torturados para confesar el crimen. Su presencia también propició la expan- sión de la toma de posición por parte de los integrantes de los dos grupos, además de haber requerido la intervención de los administradores de ambos grupos, para que se confirmara su identidad. Luego de la comparecencia de Beatriz Abagge, otros imputados en el caso estuvieron presentes en los grupos, también alegando inocencia y tortura.

Es importante señalar que el período analizado es posterior a la publicación del episodio 25, que se emitió el 10 de marzo de 2020. En él, el presentador Ivan Mizanzuk presenta contenido inédito: cintas de microcassette grabadas con las confesiones de los imputados, omitidas del proceso, pues revelaban lo que siempre habían alegado los imputados: la tortura y la construcción obligada de una narrativa considerada aceptable por la policía. En un momento destacado por Mizanzuk (2021), la acusada Beatriz Abagge afirma inventar esa narrativa. "Ahora que tenemos la cinta sin estos cortes, sabemos lo que realmente sucedió. De hecho, Beatriz, con mucha valentía, buscó de diversas formas registrar que estaba siendo coaccionada. Sólo se manipuló la cinta". (Mizanzuk, 2021, p.340). La aparición de cintas de audio inéditas dio una nueva dirección tanto al podcast como al caso policial. A pesar de que el delito está prescrito, las pruebas de tortura llevaron a los abogados defensores a solicitar una indemnización al Estado brasileño.

El marco temporal de esta investigación cubre el período posterior al lanzamiento del episodio 25 y también el final de la temporada, en noviembre de 2020. Las discusiones se derivan de los plot twists y la promesa de otros tres productos mediáticos: la serie documental de televisión, que se emitió el 13 de mayo de 2021, el libro de Mizanzuk, publicado en junio del mismo año, y el libro escrito por Beatriz y Celina Abagge, dos de las imputadas.

Hasta el 25 de abril de 2021, el subReddit Projeto Humanos Histórias reais sobre pessoas reais tuvo 3.956 participantes. La conversación estuvo relacionada principalmente con seis ejes, a saber:

- Dudas relacionadas con la prueba planteada por Ivan Mizanzuk: los participantes señalan, en las discusiones, que son más contundentes, y que la prueba presente en el proceso fue mejor utilizada en el podcast que en los jurados del caso. Estos posts estimulan el debate y se refuerzan con la polarización entre fans de uno u otro grupo de personajes de la historia. Con un tratamiento similar al de los relatos de ficción, destacan el desapego del carácter real y periodístico de la producción. Se puede decir que la intensidad del desplazamiento de la comprensión de la realidad es proporcional al nivel de compromiso de la audiencia. Es decir, los participantes con un discurso más apasionado y con mayor intensidad en la defensa de los sujetos de la historia tienden a actuar como fanáticos de manera más constante que aquellos con argumentos más razonados.

- Dudas sobre cuestiones relacionadas con la trama de los episodios: los nuevos participantes del grupo, sin haber escu- 
chado aún los 36 episodios, utilizaron el espacio de discusión para hacer preguntas sobre la trama. Estas dudas fueron respondidas por los demás miembros de los grupos. En estos momentos, la comunidad de fans se organiza, construyendo espacios de discurso: el más antiguo del grupo, el que escucha con más frecuencia los episodios, el que consume todos los productos derivados, el que construye teorías sobre los hechos de la podcast o lo que busca para obtener más información sobre el caso de fuentes no presentadas por el canon. Esta construcción de autoridad en la comunidad afecta la organización de las otras variables conversacionales identificadas en el estudio;

- Información sobre otros casos policiales reales que involucran a niños, rituales religiosos o castigos a personas inocentes: hay publicaciones en las que se señalan a otros participantes del grupo otros casos policiales, brasileños o no, que se asemejan, de alguna manera, al Caso Evandro. Esta variable se ve muy afectada por la cobertura periodística del período y la posición prejuiciosa en relación a las religiones de base africana, ya que muchas de las búsquedas estaban relacionadas con rituales de magia negra. También destacamos el impacto, en este movimiento argumentativo de las comunidades, de una serie de secuestros de niños ocurridos en la década de los noventa y que generan debates sobre la existencia de un grupo de contrabando de personas o incluso sobre el papel de un asesino en serie en el caso;

- Especulación sobre posibles culpables en el caso: con el episodio 25 y la afirmación categórica del presentador Ivan Mizanzuk de que los acusados son inocentes, ya que fueron torturados, los participantes debaten quién podría ser el responsable de la muerte del niño Evandro, entre los personajes involucrados. directa o indirectamente o en coordinación con las teorías de la conspiración. El debate sobre la culpa concierne no solo al imputado, sino a sujetos externos al caso (o modalidades de sujeto, como un asesino en serie, como mencionamos). También se refiere a los culpables de las consecuencias del proceso de investigación y juicio en la vida de los imputados - debate que involucra a personalidades como fiscales, el ex gobernador de Paraná, políticos, policías, etc;

- Teorías sobre la participación de Diógenes Caetano: el primo de Evandro, Diógenes, es considerado un personaje central en el caso, ya que fueron sus acusaciones al Ministerio Público las que resultaron en la detención de los siete imputados. Diógenes es un personaje controvertido, muy similar a las características de un antagonista en un guión de ficción. Se presenta con distintos perfiles en la narrativa. El tiempo es engañoso, víctima del tiempo, tiempo inocente. Sin embargo, su presencia está marcada en la serie -y en debates en Reddit y Facebook- incluso cuando el tema no se refiere directamente a él. Aparece en comentarios sarcásticos y argumentos razonados. Podemos decir que Diógenes es uno de los sujetos del evento que más despierta emociones y reacciones y, por tanto, teorías e hipótesis;

- Teorías de la conspiración en general: el caso Evandro es complejo e involucra acusaciones de sacrificios humanos, rituales macabros y sectas. Uno de ellos es Lineamento Universal Superior (LUS), dirigido por un brasileño y un argentino, que se encontraban en Guaratuba en ese momento. Además, uno de los lugares donde fueron trasladados algunos de los imputados es la casa de Augusto Stroessner, un ex dictador paraguayo al que se le concedió asilo político en Brasil a fines de la década de 1980. Así, hay presencia de dictadores latinoamericanos en teorías de la conspiración planteadas en las discusiones. Además, el debate sobre el papel de los políticos destacados en el estado vinculados a la familia del imputado o con los grupos policiales presentes en la ciudad también favorece la creación de teorías de la conspiración en un complejo enredo de personajes y núcleos secundarios en la narrativa;

- Información sobre lanzamientos de libros y series, y la incorporación del podcast al catálogo de Globoplay: con el acercamiento de las fechas de lanzamiento de las series documentales de TV y libros, de Mizanzuk (2021) y de las Abagge, la información sobre las fechas de lanzamiento de estos materiales se hizo común en discusiones. El debate sobre las producciones complementarias parece despertar acciones que no se podrían hacer de otra manera, ya que el final de la serie ya estaba anunciado. Las producciones derivadas actúan como refuerzo del vínculo creado entre los miembros del fandom.

Hasta el 25 de abril de 2021, el grupo de discusión de Facebook Discutindo o Caso Evandro - Projeto Humanos tuvo 6.286 par-

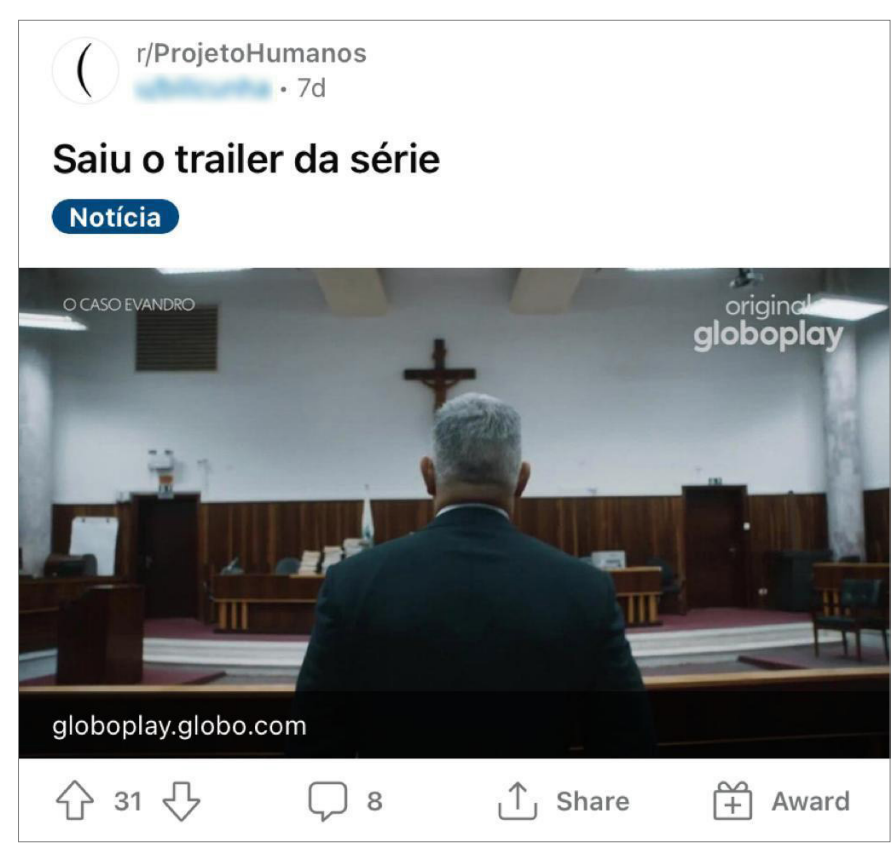

Figura 1. Información sobre extensiones transmedia del podcast. Fuente: https://www.Reddit.com/r/ProjetoHumanos/ 
ticipantes. En este caso, hay ocho ejes principales que guiaron las conversaciones:

- Compartir experiencias de podcasts y momentos de consumo: especialmente relacionado con los nuevos oyentes de podcasts, que acudían al grupo para compartir la experiencia de escucha. Aquí vemos el impacto del perfil de las redes. Facebook se caracteriza por ser un espacio para compartir información y construir teorías, pero más intensamente como un espacio de intercambios emocionales y vivenciales. Así, incluso cuando no aparece el "grupo preferente", lo emocional se coloca en el consumo compartido;

- Compartir noticias y programas sobre otros casos penales: como en el subReddit, otros casos policiales que de alguna manera se asemejan al caso Evandro se presentan como otras opciones narrativas para quienes disfrutaron viendo el podcast. Estas presentaciones de casos similares surgen tanto para reforzar el grupo elegido en la narrativa y su papel de inocencia o culpabilidad como para demarcar problemas encontrados, como el prejuicio contra las religiones afrobrasileñas o una supuesta incompetencia del sistema de Justicia;

- Discusión de teorías sobre el crimen, con investigación por reportes externos / complementarios: sale a relucir el lado investigativo de los participantes, presentando materiales que no están listados en la wiki de Caso Evandro y que pueden traer nueva información sobre el caso. Esta organización

\section{5 de fevereiro $\cdot \quad$ compartilhou um link. $\quad \ldots$}

Pessoal, bom dia!

Próxima quinta-feira, eu e 2 professores iremos fazer uma 'análise' ao vivo de alguns trechos da fita K7 do Caso Evandro.

Eu já fiz esse tipo análise em alguns treinamentos, e dessa vez nós iremos fazer algumas pontuações ao vivo.

Não é um trabalho investigativo com a qualidade do Ivan, é uma parte técnica envolvendo protocolos de análise de credibilidade.

Os que quiserem assistir, serão bem vindos.

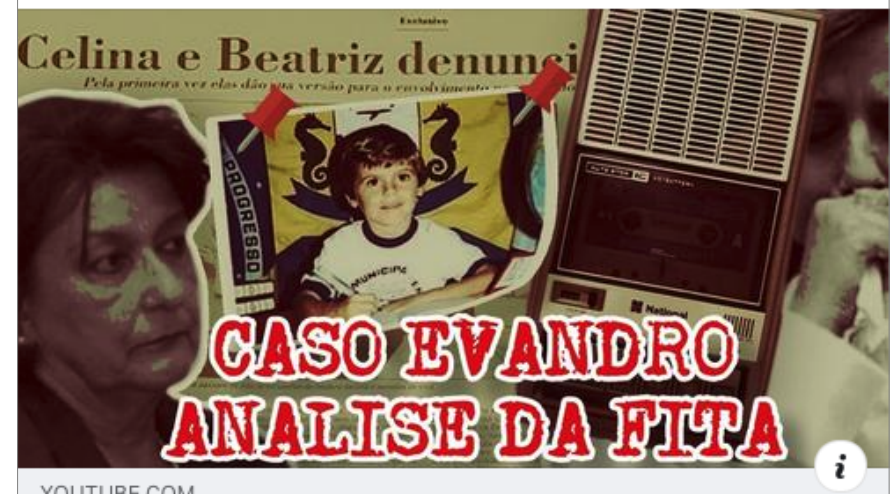

YOUTUBE.COM

Caso Evandro - Análise da Fita K7 Ao Vivo

o Caso Evandro ficou conhecimento mundialmente. Ainda sem escla...

(b) 111 20 comentários

Figura 2. Nuevas investigaciones del público, a partir de los materiales disponibles en la wiki. Fuente: https://www.Facebook.com/groups/2097956850321307 es característica de la audiencia narrativa transmedia y uno de los principales referentes del engagement de la audiencia - relacionada con el concepto de autoridad y detención de la información, que también se relaciona con los dos ejes siguientes;

- Debate sobre causas y culpables: con el episodio 25 surgen nuevas lagunas en el caso Evandro, abriendo posibilidades de debate sobre quién pudo haber asesinado al niño y por qué. El debate sobre causas y culpables impregna toda la temporada de podcasts y se refleja en todos los espacios de diálogo de los fans, pero cobró fuerza a partir de este episodio, estimulado por el posicionamiento del presentador;

- Defensa directa de las Abbage: se amplió la voz de los participantes del grupo que defendían la inocencia de Beatriz y Celina Abagge, acusadas del crimen, también del episodio 25 de la cuarta temporada del podcast, que atrajo a nuevos seguidores a su lado. Es interesante notar que aunque nuevos seguidores han definido su posición sobre el caso en este momento, hay un grupo leal que siempre ha defendido a las Abbage en el grupo de Facebook, recurriendo más que en el subReddit a argumentos emocionales y, en ocasiones, a la defensa apasionada y agresiva de ambas. No sucedió lo mismo, tan explícitamente, con los otros imputados;

- Ataques y burlas contra Diógenes Caetano: al primo de Evandro se le llama con nombres despectivos y, en algunos temas

\section{1 de abril . $\rightarrow$ fez uma pergunta $?$.
Isso é sério ou é primeiro de abril?
Estou NERVOSA!}

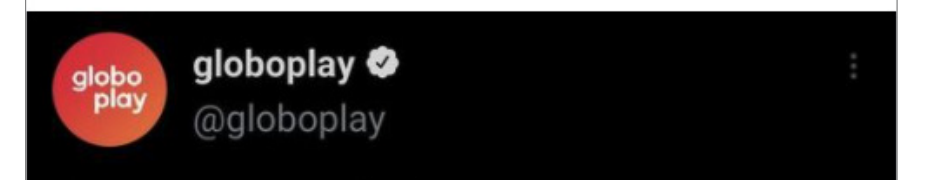

\section{Trago as verdades:}

\section{Onde Está Meu Coração chega}

04/05 por aqui $\checkmark$ Caso Evandro chega em maio por aqui $\checkmark$ How I Met Your Mother vai entrar no meu catálogo $\checkmark$ 21:00 01 abr. $21 \cdot$ Twitter Web App

(1) 49 13 respostas

Figura 3. Información sobre extensiones transmedia del podcast. Fuente: https://www.Facebook.com/ groups/2097956850321307 
de debate, se cuestiona su posición relacionada con el caso. Este eje puede considerarse similar a un relieve cómico en la narrativa. Más que en el subReddit, en Facebook, las bromas y el ridículo del personaje superpusieron su protagonismo en el evento;

- Manifestación de ansiedad por el lanzamiento de la serie y los libros: en el grupo de Facebook también son comunes las manifestaciones sobre el lanzamiento de la serie documental de televisión y los dos libros que discuten el caso, todos puestos a disposición después del período de análisis;

- "Análisis" del caso: a partir de impresiones personales y sin fundamento en los documentos presentados en la wiki, algunos participantes del grupo analizan el caso Evandro. La falta de razonamiento conduce a debates con los demás miembros del grupo, que indican información y fuentes adicionales. Sería un enfoque educativo, equivalente a aclarar dudas sobre la trama subReddit, pero con un enfoque más apasionado, especialmente en los casos que involucran la dicotomía inocencia vs culpa.

\section{Consideraciones finales}

La observación de las conversaciones de los fanáticos del podcast Projeto Humanos en su cuarta temporada, 0 Caso Evandro, demuestra que los podcasts narrativos, especialmente aquellos que utilizan técnicas de storytelling, brindan una mayor inmersión para el público. El audio, que ya se considera inmersivo, gana, con estas técnicas y la modalidad narrativa, fieles oyentes, que se sumergen en las tramas y las llevan más allá del audio, siguiendo las historias y expandiéndolas en otros medios, soportes o plataformas. Es el éxito de la narrativa de 0 Caso Evandro lo que hizo que se retomara la trama legal, nuevos elementos por descubrir y nuevas extensiones transmedia pudieron aparecer y circular.

Aliado al audio como eje vertebrador de la narrativa, tenemos la serialidad (Teixeira, 2020) como elemento presente en la temporada. La narrativa que se desarrolla en capítulos y, dentro de ellos, en arcos narrativos entrelazados, proporciona una expansión de las formas en que la audiencia se conecta con el objeto. Por lo tanto, los capítulos terminan en ganchos que llaman a la audiencia al siguiente capítulo. En el caso de la cuarta temporada, también hay espacios más grandes entre los episodios, que aquí se denominan micro temporada. Los ganchos que dejó el presentador Ivan Mizanzuk entre episodios y descansos programados llevaron a una intensa conversación entre los fanáticos de los podcasts en los dos grupos analizados y también en otros grupos existentes en otras plataformas.

También es de destacar que la presencia de personajes de la trama real, que ingresaron a los dos grupos analizados, ha provocado una intensificación de los debates. En el período analizado, encontramos más expresiones de apoyo a Beatriz Abagge, ya que los 120 días de análisis se realizaron luego de la divulgación de las grabaciones que confirman la tortura e inocencia de los siete imputados. Antes del episodio 25, que aclara las torturas, se cuestiona la presencia de Beatriz Abagge en ambos grupos, como si pudiera sesgar el debate. Tras la liberación de las cintas inéditas, otra acusada, Celina Abagge, y algunos de sus familiares aparecen en el debate de Facebook. Osvaldo Marcineiro y Airton Bardelli, acusados del crimen, también se unieron al grupo de discusión de Facebook. La presencia del imputado hace aflorar interrogantes, apoyos y otras acusaciones, fomentando también el debate.

Los grupos de discusión analizados aparecen, en el período analizado, como espacios propicios para la especulación de los fanáticos del podcast. Puntos sueltos de la trama, preguntas sin respuesta, nuevas historias de prensa descubiertas en el archivo, la actuación de los personajes en la actualidad son motivos para que el público hable y especule sobre la dirección de la trama, tanto del podcast en sí como de los hechos en los que se basa. Así, también es posible identificar que la narrativa real se transforma momentáneamente en una narrativa cercana a la ficcional: se buscan pistas y se trabaja la construcción de tramas que justifiquen opiniones, a partir de datos presentados en el audio y en la wiki. Se especula, sobre todo después de la confirmación de las torturas, quiénes son los verdaderos culpables del crimen y cuáles son los motivos detrás de él. Las discusiones crecen como si los fanáticos estuvieran en una carrera para descubrir, en primer lugar, quién mató a Evandro y por qué.

Ya hemos señalado que la audiencia comprometida fue importante en las decisiones sobre la producción de extensiones transmedia de la trama. El análisis de las publicaciones en ambos grupos demuestra que el público, especialmente los fanáticos de los podcasts, también juega un papel fundamental en la difusión de la narrativa, tanto para los nuevos oyentes como para los nuevos polemistas, agregados a los grupos. El último episodio de esta temporada del podcast ya se ha emitido, al igual que todos los episodios de la serie documental, y ambos libros ya han sido lanzados. Aun así, nuevos miembros se unen a los grupos y retoman la discusión, ampliando el alcance de la narrativa original.

Con el análisis aquí presentado, observamos que los podcasts narrativos se caracterizan por ser propicios para captar a la audiencia, hacer que los oyentes se conviertan en audiencias fieles y activas y que, finalmente, puedan elevarse a la categoría de fans. En un mundo donde el compromiso público se muestra como un factor decisivo para el mantenimiento de proyectos, tanto periodísticos como de ficción, salen adelante podcasts narrativos de crimen real y misterio, como el caso de la cuarta temporada de Projeto Humanos. La audiencia cumple su rol y fortalece una cadena de discusiones que, además de expandir oyentes, hace que el debate crezca y reverbere más 
allá del audio original. Así, tenemos un campo abierto para ser explorado por locutores y narradores de podcasts que sepan contar buenas historias y, con ellas, captar a la audiencia.

\section{Notas al final}

1. Jenson (1992) aborda dos vertientes peyorativas del comportamiento excesivo de los aficionados: la obsesión individual y la turba histérica. Ambas cosas, según la autora, indican que el comportamiento de los aficionados se considera disfuncional, desviado o incluso peligroso. El fan obsesivo individual, influenciado por los medios de comunicación, desarrolla fantasías, acosa y puede llegar a matar al ídolo. La multitud histérica, por su parte, es la que se reúne y grita en los aeropuertos o en las puertas de los hoteles para atraer la atención del ídolo o para apoyar a un equipo deportivo, con comportamientos que se tildan de depravados o animales. Para ella, los comportamientos excesivos dicen más de la sociedad contemporánea, fragmentada, vulnerable y cada vez más solitaria, colaborando, además, a determinar que el público que no se autodenomina fan no tenga conexión emocional con las producciones mediáticas y sus personajes. Jenkins (2015) cree que los adjetivos patológicos que acompañan a los comportamientos de los fans no se corresponden con la realidad, y plantea cómo la participación de la audiencia ha cambiado el escenario de las producciones mediáticas, dando lugar a nuevas prácticas que buscan el engagement.

2. Para Lopez (2017), la incorporación de elementos no sonoros - o no exclusivamente sonoros - es parte de la comprensión de la nueva radio. Aunque la autora defienda la importancia del eje narrativo sonoro en la radio, señala el destacado rol de contenidos visuales, multimedia, que pueden presentarse como complementarios o alternativos al sonido en la narrativa radiofónica contemporánea. La autora señala también que la complementación y el enredamiento narrativo de las plataformas son cruciales para la comprensión de la radio en plataformas digitales.

\section{Bibliografía}

Adorno, T. W., y Horkheimer, M. (1985). Dialética do esclarecimento: fragmentos filosóficos. Jorge Zahar Ed.

Alzamora, G., y Tarcia, L. (2012). Convergência e Transmídia: galáxias semânticas e narrativas emergentes em jornalismo. Brazilian Journalism Research, 8(1), 22-35. https://bjr.sbpjor.org.br/bjr/article/ view/401

Bonini, T. (2015). The 'second age' of podcasting: reframing podcasting as a new digital mass medium. Quaderns del CAC, XVIII(41), 21-30. https://www.cac.cat/sites/default/files/2019-01/ Q41_Bonini_EN_0.pdf

Cordeiro, W., y Costa, L. (2016). Jornalismo imersivo: perspectivas para os novos formatos. Leituras do Jornalismo, ano 3(2), 99- 116. https://www3.faac.unesp.br/leiturasdojornalismo/index.php/leiturasdojornalismo/article/view/114

Domínguez-Martín, E. (2015). Periodismo inmersivo o cómo la realidad virtual y el videojuego influyen en la interfaz e interactividad del relato de actualidad. El profesional de la información, 24(4), 413-423. https://doi.org/10.3145/epi.2015.jul.08

Ferraretto, L.A. (2014). Rádio: teoria e prática. Summus.

Jenkins, H., Green, J., y Ford, S. (2014). Cultura da conexão. Criando valor e significado por meio da mídia propagável. Aleph.

Jenkins, H. (2009). Cultura da convergência. Aleph.

Jenkins, H. (2015). Invasores do texto: fãs e cultura participativa.
Marsupial Editora.

Jenson, J. (1992). Fandom as Pathology: The Consequences of Characterization. En Lewis, L (Ed.). The Adoring Audience: fan culture and popular media, (pp. 9-26). Routledge.

Kischinhevsky, M. (2016). Rádio e mídias sociais: mediações e interações radiofônicas em plataformas digitais. Mauad X.

Lessa, R. (2020). Seriados de TV e narrativa transmídia: Explorando o universo ficcional de True Blood. EDUFBA.

Lévy, P. (2003). A inteligência coletiva: por uma antropologia do ciberespaço. Loyola.

Lindgren, M. (2014). 'This Australian life': the Americanisation of radio storytelling in Australia. Australian Journalism Review, 36(2), 63-75. https://doi.org/10.4225/03/5a16043664b88

Lindgren, M. (2016). Personal narrative journalism and podcasting. The Radio Journal: International Studies in Broadcast and Audio Media, 14(1), 23-41. http://dx.doi.org/10.1386/rjao.14.1.23_1

Lopez, D.C. (2016). (Re)Construindo o conceito de audiência no rádio em cenário de convergência. En: Zuculoto, V., Lopez, D. C., Kischinhevsky, M. (Eds.). Estudos Radiofônicos no Brasil: 25 anos do Grupo de Pesquisa de Rádio e Mídia Sonora da Intercom. INTERCOM.

Lopez, D. C. (2017). La radio en narratives immersives : le contenu journalistique et l'audience. Cahiers d'histoire de la radiodiffusion, (132), 103-116.

Lopez, D. C., Viana, L., y Avelar, K. (2018). Imersividade como estratégia narrativa em podcasts investigativos: pistas para um radiojornalismo transmídia em In the Dark. Anais do $27^{\circ}$ Encontro Anual da Compós. Compós.

Martínez-Costa, M. P., Müller, M.J. y Villar, M. (2020). La expansión del podcast en la radio pública: estudio comparado de Radio Nacional Argentina y Radio Nacional de España (2019). Hipertext.net, (20), 55-67. https://doi.org/10.31009/hipertext.net.2020.i20.05

Masip, P. (2014). Audiencias activas, democracia y algoritmos. Anuario ThinkEPI, 8, 260-263. https://thinkepi.profesionaldelainformacion. com/index.php/ThinkEPI/article/view/29590

Masip, P. (2015). Nuevos retos en la gestión de los contenidos generados por la audiencia: el caso de Charlie Hebdo. Anuario ThinkEPI, 9, 168-171. https://doi.org/10.3145/thinkepi.2015.40

McHugh, S. (2016). How podcasting is changing the audio storytelling genre. The Radio Journal - International Studies in Broadcast $\&$ Audio Media, 4(1), 65-82. https://ro.uow.edu.au/cgi/viewcontent.cgi?article=3366\&context=lhapapers

Mizanzuk, I. (2021). O Caso Evandro: Sete acusados, duas polícias, o corpo e uma trama diabólica. Harper Collins.

Palacios, M. (2003). Ruptura, continuidade e potencialização no jornalismo on-line: o lugar da memória. En Machado, E.; Palacios, M. (Eds.). Modelos de jornalismo digital, (pp. 1-17). Calandra.

SCOLARI, C. (2013). Media Evolution: Emergence, Dominance, Survival, and Extinction in the Media Ecology. International Journal of Comunication, (7), 1418-1441. https://ijoc.org/index.php/ijoc/article/ view/1919

Shirky, C. (2011). A cultura da participação: criatividade e generosidade no mundo conectado. Zahar.

Shirky, C. (2012). Lá vem todo mundo: o poder de organizar sem organizações. Zahar. 
Teixeira, J. S. (2020). Regimes de serialidade. Benditas.

Thompson, J. B. (1998). A mídia e a modernidade: uma teoria social da mídia. Vozes.

\section{CV}

Debora Cristina Lopez. Doctora en Comunicación y Cultura Contemporánea de la Universidad Federal de Bahía, con estancias posdoctorales en Comunicación en la Universidad Federal de Río de Janeiro y en la Universidad del Estado de Río de Janeiro. Profesora de los Postgrados en Comunicación de la Universidad Federal de Ouro Preto y de la Universidad Federal de Paraná. Coordinadora del Grupo de Investigación de Convergencia y Periodismo (ConJor), del Laboratorio de Innovación en Periodismo (Labin) y del Centro Hipátia de Formación para la Divulgación de la Ciencia, todos en la UFOP. Coordina el Grupo de Investigación de Radio y Medios Sonoros de Intercom y preside la Junta Directiva de la Red de Radios Universitarias de Brasil. Es autora de "Radiojornalismo Hipermidiatico" (LabCom Books, Covilhã), así como de artículos en revistas y capítulos de libros. https://www.conjor.com.br/
Aline Monteiro Homssi. Estudiante de doctorado en Comunicación del Programa de Posgrado en Comunicación Social de la Universidad Federal de Minas Gerais (UFMG). Máster en Comunicación de la Universidad Federal de Ouro Preto (UFOP). Especialista en Comunicación y Gestión Empresarial por el Instituto de Educación Continuada de la Pontificia Universidad Católica de Minas Gerais (IEC - PUC-Minas). Licenciada en Comunicación Social - Título de Periodismo por la Pontificia Universidad Católica de Minas Gerais (PUC-Minas). Investigadora asociada al Grupo de Investigación de Convergencia y Periodismo (ConJor - UFOP) y al Subgrupo MediaAção (UFMG), miembro del Centro de Investigaciones y Conexiones Intermedias (NucCon - UFMG). Investiga la cultura de los fans, las series de televisión y las dinámicas transmedia.

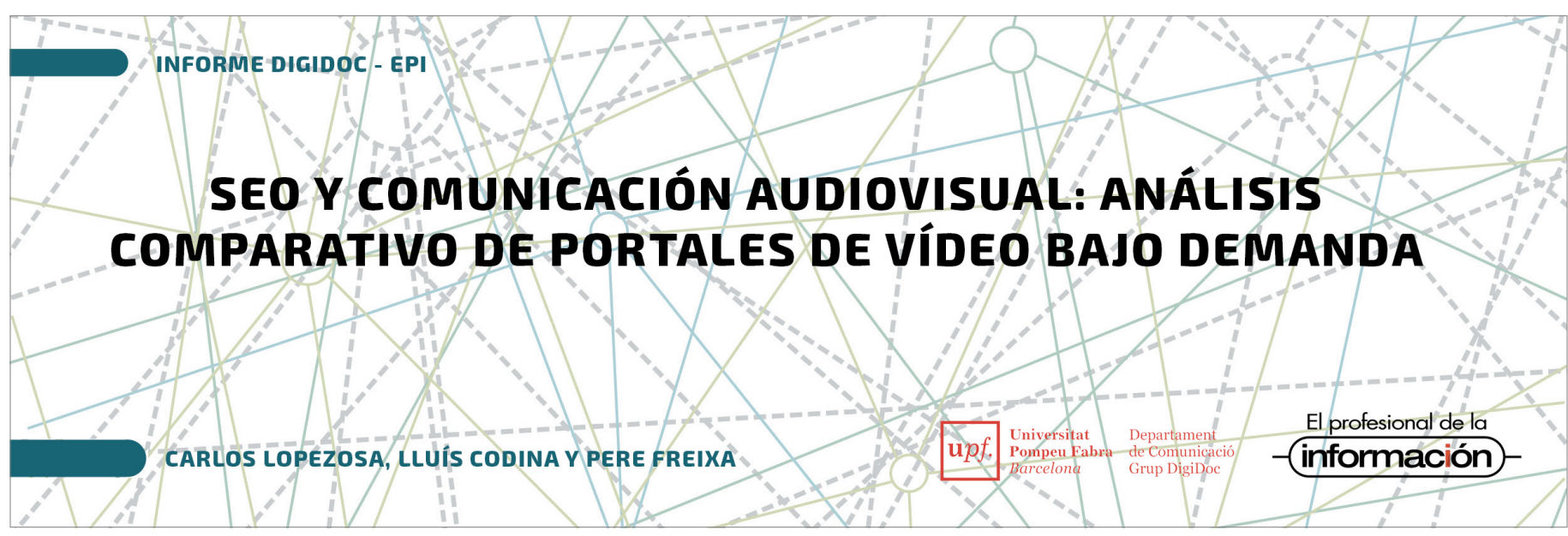

\section{.

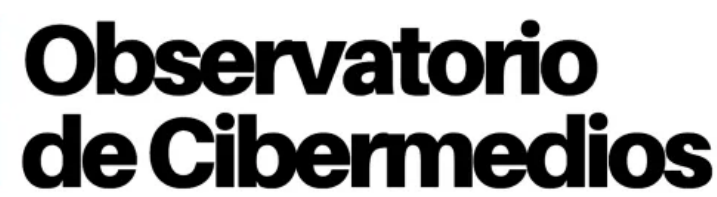

https://observatoriocibermedios.upf.edu/

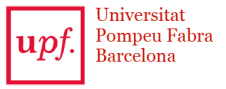

Departamento
de Comunicación
Grupo DigiDoc

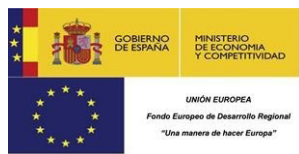

El Observatorio de Cibermedios es una producción del Grupo de Investigación en Documentación Digital y Comunicación Interactiva (DigiDoc) del Departamento de Comunicación de la Universitat Pompeu Fabra.

El Observatorio de Cibermedios (OCM) forma parte del proyecto del Plan Nacional "Narración interactiva y visibilidad digital en el documental interactivo y el periodismo estructurado". RTI2018-095714-B-C21 (MINECO/FEDER), Ministerio de Ciencia, Innovación y Universidades (España). 